\title{
APPLIED ELEMENT MODELLING AND PUSHOVER ANALYSIS OF UNREINFORCED MASONRY BUILDINGS WITH FLEXIBLE ROOF DIAPHRAGM
}

\author{
Rohit K. Adhikari* and Dina F. D'Ayala \\ Department of Civil, Environmental and Geomatic Engineering, University College London, London, \\ United Kingdom \\ \{rohit.adhikari.15, d.dayala\}@ucl.ac.uk
}

\begin{abstract}
Old and poorly constructed unreinforced masonry buildings are inherently vulnerable to earthquakes. Seismic analysis and assessment of these buildings with flexible diaphragms i.e. without box behavior is challenging as the available assessment methods for reinforced concrete framed or masonry structures with rigid diaphragms are not directly applicable to these buildings. In such structures, the walls loaded in out-of-plane direction and those loaded in in-plane direction behave in significantly different ways during earthquakes, making a conventional global analysis ambiguous and unreliable. In this study, using the applied element method for numerical modelling and analysis, a simple and reliable methodology for seismic performance assessment of unreinforced masonry buildings with flexible roof diaphragm is presented which includes the out-of-plane behavior in the global analysis. The applicability of the methodology for subsequent steps in fragility and vulnerability assessment of such buildings using non-linear static procedures is also clarified.
\end{abstract}

Keywords: Unreinforced Masonry Building, School Building, Applied Element Method, Out-of-Plane Behavior, Pushover Analysis, Seismic Performance Assessment 


\section{INTRODUCTION}

It is observed that old and poorly constructed unreinforced masonry (URM) structures are susceptible to partial damage or collapse even under light to moderate earthquake shaking [13]. In URM buildings, one of the key construction features in controlling the seismic performance is the level of connection between the URM walls and the horizontal structures [4]. When floors and roof don't have enough in-plane rigidity or are not properly connected to the URM walls, then the floors or roof act as a flexible type diaphragm and the commonly held assumption that all vertical structures at a story level will displace by the same amount, does not hold true. This has implications for the validity of results obtained by performing a conventional pushover analysis of such structures, hence the main aim of this paper is to present a valid strategy for pushover analysis and seismic performance assessment of URM buildings with flexible roof diaphragm.

When considering individual URM walls, the out-of-plane (OOP) response is weaker compared to the in-plane (IP) response, mainly because only the tensile capacity is mobilized dependent on cohesion, instead of the shear capacity which benefits from both cohesion and friction. Moreover, the out-of-plane behavior is also usually affected by lower stiffness and, in slender walls, subjected to P-Delta effects. Conversely, in 3-D global building configurations, where cross-walls are connected to each other as well as to the horizontal structures, the walls acting in OOP direction have better seismic behavior than a single detached wall because of the frictional resistance at the cross-wall connection and the displacement constraint provided by the horizontal structures. A comprehensive overview of the different OOP failure mechanisms of URM walls in existing buildings is presented in D'Ayala and Speranza [5]. Observations from several post-earthquake damage surveys $[2-3,6]$ have shown that the OOP failure modes have caused significant damage in URM structures with flexible diaphragms. Several experimental studies on such buildings [7-8] have also proven that partial or full OOP collapse are most likely to occur when the diaphragms are flexible or if the diaphragm to wall connections are poor. There are several experimental [9-12] and analytical as well as numerical [5, 13-15] works investigating the lateral OOP behavior and failure mechanisms of URM walls. A good review of the assessment methods (force-based and displacement-based methods as well as recommendations given in codes and standards) for OOP behavior of URM walls is presented in Ferreira et al. [16] and Sorrentino et al. [17]. It is observed that so far developed force-based procedures are conservative in terms of displacement capacity of OOP walls and the displacement-based procedures are based on few and specific experimental scenarios [16]. There are some issues that are still challenging in the reliable seismic assessment of OOP behavior in 3D URM buildings when using these simplified approaches. First is the simplification of the boundary conditions. In real structures, the boundary conditions are not always rigid or simply supported as assumed in simplified assessment approaches [15]. Further, the extent of boundary conditions can vary depending on the strength of connections to the cross-wall or the geometry (e.g. opening position) and the material quality in the cross-walls. Consequently, the OOP collapse mechanism can involve just the separation of inter-locking at the connection or it can include certain portion of cross-walls to form a combined failure mechanism [5, 14]. Secondly, the presumed crack patterns have limitations and can change depending on either the geometry (e.g. wall aspect ratio, brick laying pattern) or mechanical properties of masonry or loading conditions.

In the assessment of global seismic behavior of URM structures with flexible diaphragms, many researchers have neglected or given little importance to OOP behavior and failure modes [e.g. 18-21]. This is mainly because of two reasons: the lack of real-world experimental works to characterize and quantify the load-deformation behavior in the OOP behavior and the 
difficulty of modelling the large non-linearity attained by the walls in the OOP deformation before failure using FEM based procedures.

Pushover analysis based seismic performance assessment methods such as capacity spectrum method [22] and N2 method [23] are computationally efficient alternatives to time history analysis. In reinforced concrete or masonry structures with rigid diaphragm, the global seismic analysis can easily be carried out as the building's behavior can be idealized as that of a single degree of freedom (SdoF) system. However, in flexible diaphragm type URM structures, because of the substantial difference in stiffness and displacement capacity, walls acting in IP and OOP directions usually have significantly different natural frequency of vibration and mode shapes, and hence it becomes inaccurate to represent the whole building with one SdoF system. A logical simplified approach to conduct global analysis of such buildings is currently lacking in literature.

Thus, this paper is focused on the development of a methodology for conducting non-linear static procedure based global seismic performance assessment of URM structures with flexible roof diaphragm. The paper is structured as follows: Section 2 introduces the overall methodology for the pushover-based seismic performance assessment of URM structures with flexible roof diaphragm within which the application of applied element method for the numerical modelling and analysis of URM structures is also discussed. Section 3 of the paper introduces the construction characteristics of the case study URM building typology. Section 4 presents and discusses the results from this study. Finally, some conclusions and recommendations are presented in Section 5.

\section{METHODOLOY FOR SEISMIC PERFORMANCE ASSESSMENT OF URM BUILDINGS WITH FLEXIBLE ROOF DIAPHRAGM}

The overall methodology for the non-linear seismic performance assessment of single storied URM buildings with flexible roof diaphragm is presented in Figure 1. The first step involves the collection of geometrical data and identification of reliable material properties either via experimental tests or from literature on similar construction types. In the second step, the 3-D numerical model of the building is created which includes all the load bearing structures, appropriate material constitutive laws and boundary conditions. Finite element based, discrete element based, combined finite/discrete element based or applied element-based modelling tools can be used. The modelling environment should be able to simulate both the IP and OOP behavior of URM walls and the interaction among these walls as well as with the horizontal structures. In the next step, a global pushover analysis is conducted on the numerical model in which the model is subjected to an increasing lateral force pattern in a direction until global collapse is reached. By employing a global pushover analysis on a 3-D model, effects of crosswall and diaphragm inter-actions are included in the load-deformation behavior of individual walls. From the results of this analysis, one can generate the pushover curves for each single IP and OOP walls by recording and plotting the base shear and the top displacement in the individual walls at each step of loading. If the displacement history for all the walls acting in IP (or OOP) direction are similar, then global IP (or OOP) pushover curves can be generated by summing up the individual wall's base shear and computing the average displacement of the walls at each particular instant of the analysis. Then, the seismic performance assessment using capacity spectrum approach or N2 method can be conducted at each wall level or at global IP or OOP level. Finally, these results can be interpreted at individual wall level, global IP or OOP level or even at global building level. These different steps are further discussed in the subsections below. 


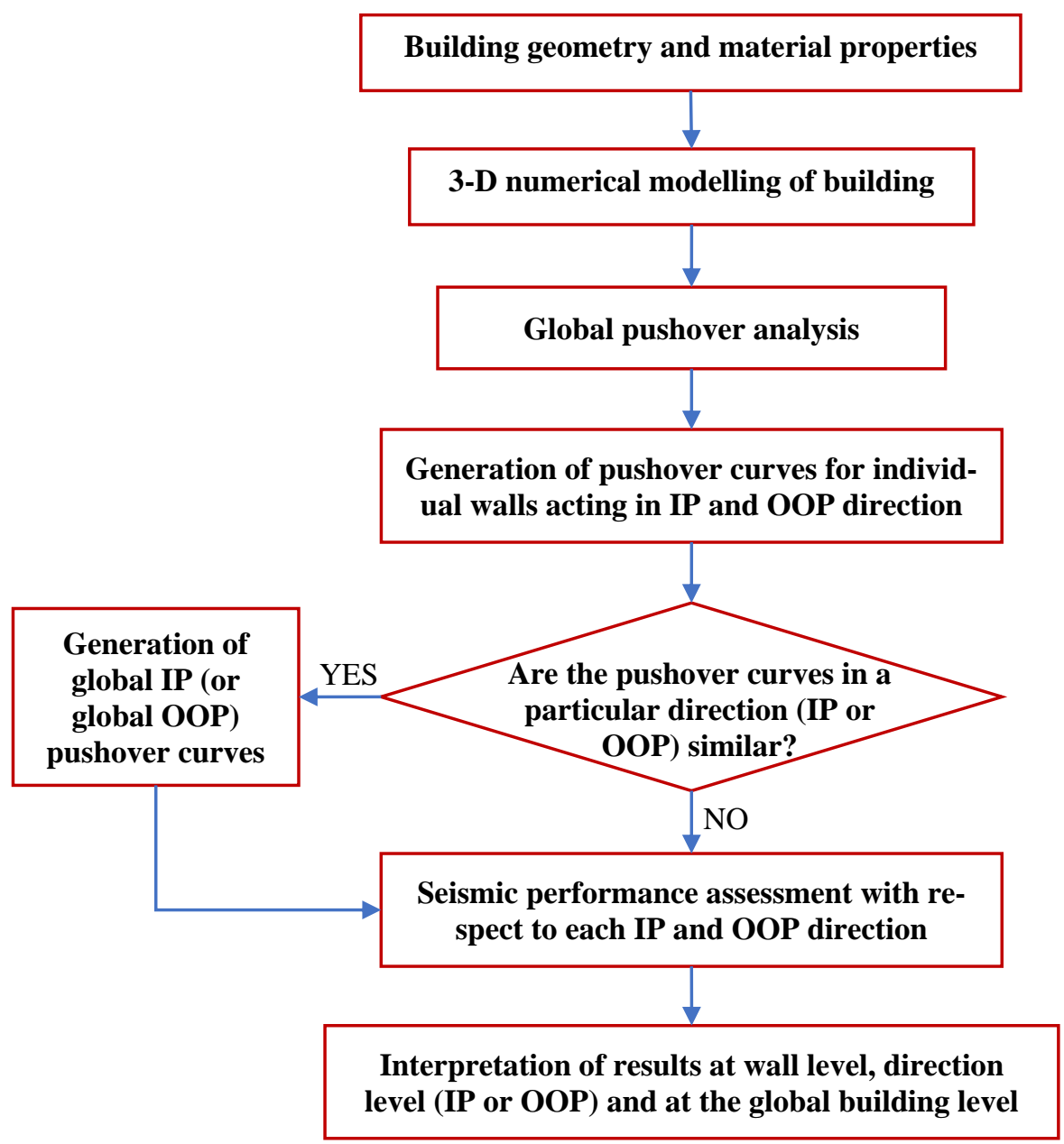

Figure 1: Methodological approach for seismic performance assessment of single storied URM buildings with flexible roof diaphragm.

\subsection{Numerical modelling of unreinforced masonry}

Different modelling environments and strategies have been used for numerical modelling of masonry, e.g. limit analysis based methods [e.g. 5], finite element based methods [e.g. 24], discrete element based method [e.g. 25], applied element based methods [e.g. 26], equivalent frame based method [e.g. 27] etc. Each method has pros and cons and comparison of these different methods is beyond the scope of this paper. Applied element method is used in the present study and is briefly discussed below.

Applied element method (AEM) [28], an improved variation of distinct element method, allows us to model the blocky and discontinuous nature of masonry structures. In AEM, a structure is modelled as an assembly of rigid elements connected to each other by means of distributed deformable springs. Several past studies [26, 29-30] have proved the applicability of the applied element method in simulating the crack initiation, propagation and large displacement response of URM structures under static and dynamic loading. As the global 3-D behavior of URM structures including the interaction of cross-walls can be studied, from the crack initiation to complete collapse with reliable accuracy, Extreme Loading for Structures (ELS) software [31], based on AEM, is used in the present study for the numerical modelling and pushover analysis.

In AEM, masonry is usually modelled by adopting simplified micro-modelling technique (Figure 2). Two types of springs are used, viz. 'unit' or 'element' springs connecting the applied 
elements of the units, and 'joint' springs connecting the individual applied elements to represent the equivalent properties of mortar and mortar-unit interface. A detailed overview of the formulation, constitutive laws, failure criteria etc. for masonry modelling in AEM can be found in Malomo et al. [26].

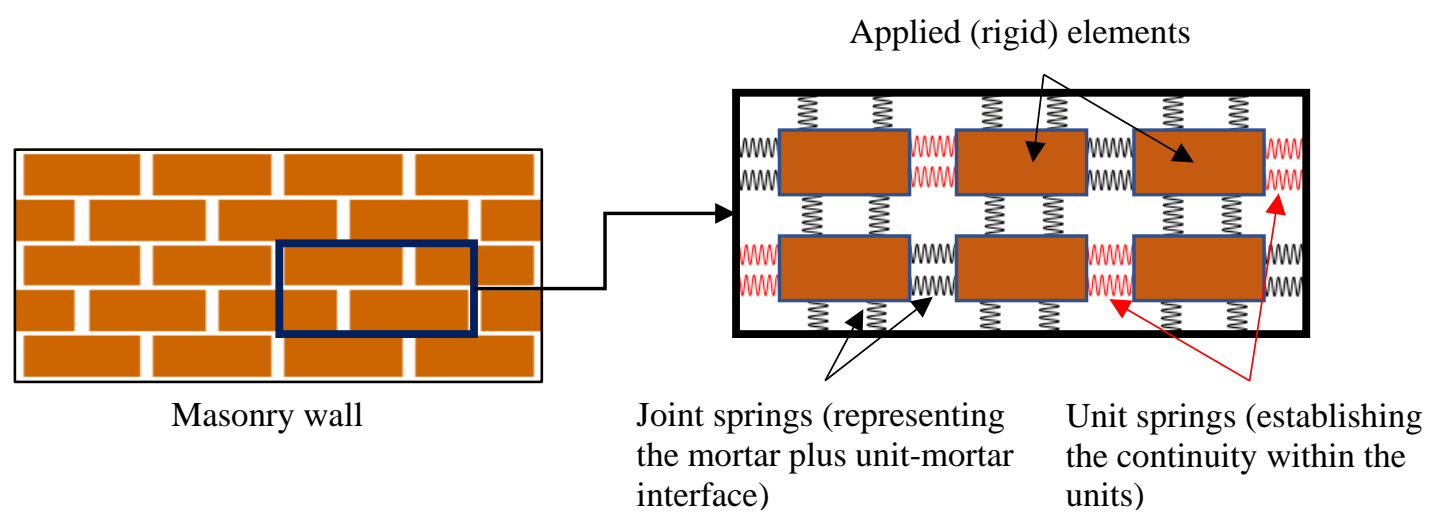

Figure 2: Schematic of the simplified micro-modelling of masonry using AEM.

\subsection{Global non-linear pushover analysis}

Conventional pushover analysis [e.g. 32] of masonry structures modelled using element-byelement modelling technique, with discontinuous joint represented by springs with finite strength and stiffness that can separate during loading, is complex as the application of pushover force or displacement imposed on the structure often causes stress concentration on a particular element or region thereby causing local failure without affecting the rest of the structure. Thus, in the present study, a different approach for applying pushover loading is proposed in which the numerical model is subjected to a linearly increasing ground acceleration, rather than a force pattern on the structure, until collapse. This works by applying an increasing 'effective earthquake force' on the structure. In masonry structures represented by element-to-element modelling, each of the elements with same mass will get same force exerted on it. Thus, if the mass of the structure is uniformly distributed along the height, the proposed pushover loading will cause a uniform force pattern applied along the height. Such analysis represents a force-based non-linear pushover analysis, as opposed to the displacement-based pushover analysis, usually implemented for framed structures.

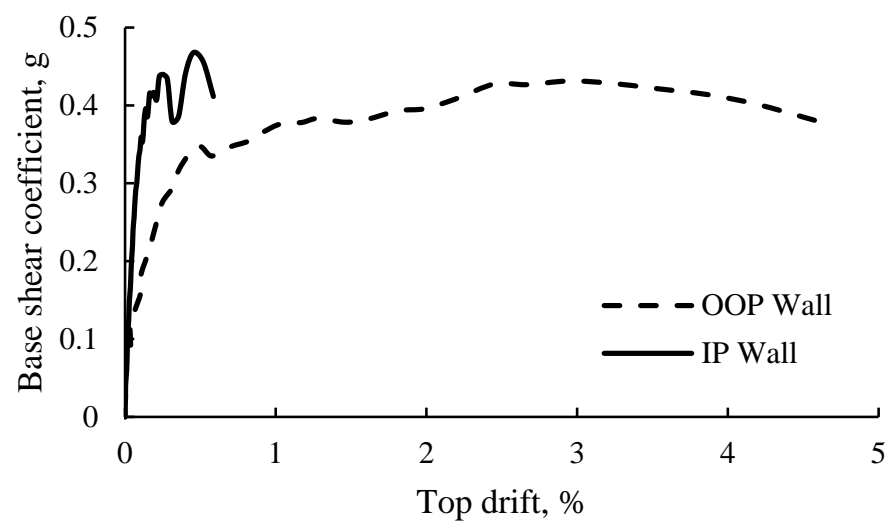

Figure 3: Example capacity curves for walls acting in IP and OOP directions for an URM building with flexible roof diaphragm. 
When a global pushover analysis is conducted for a 3-D building with flexible roof diaphragm, the force-deformation behavior for each wall, acting in IP and OOP directions, can be generated by recording the base shear resisted by the wall and the corresponding wall top displacement along the pushover loading direction, at each step of loading. Usually, the initial stiffness and hence the natural frequency of vibration and mode shapes, maximum capacity and the ultimate displacement of walls acting in IP direction and those acting in OOP direction are significantly different (Figure 3 ) and it will be meaningless to combine such curves to produce a global one as the deformation and base shear are attained for each wall following a different rate of load-deformation histories.

The damage states of individual walls within the global pushover analysis can also be observed to identify the thresholds of different damage states in terms of wall drift. With this information, procedures such as N2 method [23,33] can be applied to each wall to determine its seismic performance with respect to response spectra and damage threshold, and thereby derive fragility and vulnerability functions at individual wall level. For simplicity and computational efficiency, if the walls acting in a particular (IP or in OOP) direction have similar geometry and mass distribution, and hence similar load-deformation behavior, then seismic performance at global IP or global OOP level can be conducted by generating the global pushover curves for IP behavior (or OOP behavior), separately, using equations (1) and (2). However, it should be noted here that the individual walls acting in a particular direction are not coupled.

The total base shear and corresponding average roof displacement for global IP (or OOP) behavior:

$$
\begin{aligned}
& V_{G, I P(\text { or } O O P)}=\sum_{i=1}^{n} V_{i, I P(\text { or } O O P)} \\
& d_{G, I P(\text { or } O O P)}=\frac{\sum_{i=1}^{n} d_{i, I P(\text { or } O O P)}}{n}
\end{aligned}
$$

Where, $V_{i, I P(\text { or OOP })}$ and $d_{i, I P(o r O O P)}$ are the base shear and the roof displacement, respectively of the $i^{\text {th }}$ wall acting in IP (or OOP) direction and $n$ is the number of walls in a particular (IP or OOP) direction.

Finally, these individual wall level (or global IP or OOP level) results can be combined to understand the building level seismic vulnerability of URM structures with flexible roof diaphragm.

\section{EXAMPLE CASE STUDY BUILDING TYPOLOGY}

To show the application of the proposed methodology, a single-story index building of URM (brick in cement mortar) school typology from Nepalese school building portfolio is considered as the case study building. Figure 4 and Figure 5 show some representative photographs and a typical plan of these school buildings, respectively. These buildings are mostly rectangular in plan and single storied with a double pitched light roof structure. The story height is about $3 \mathrm{~m}$. Such URM school buildings are widely present worldwide in many countries [34-35]. For example, in Nepal, more than $60 \%$ of the total school portfolio consists of URM construction [36] and a large share of these construction types are old and were designed and constructed before either development or implementation of seismic design codes in the country. Nonetheless, residential buildings of similar construction types also exist in many developing countries [30, 37]. 


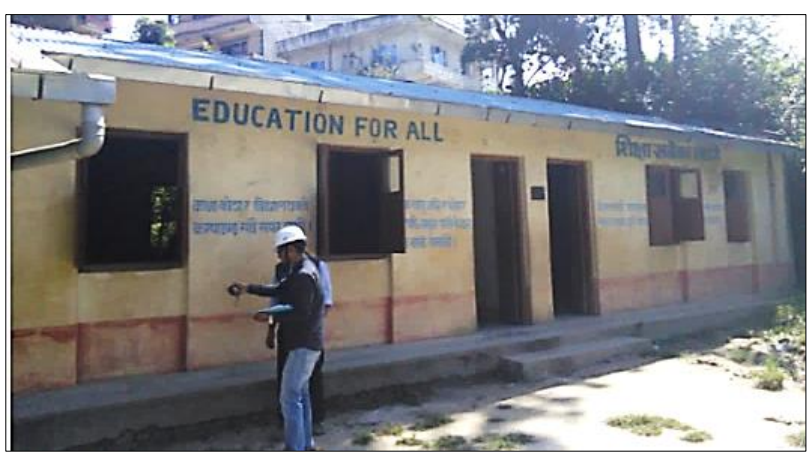

(a)

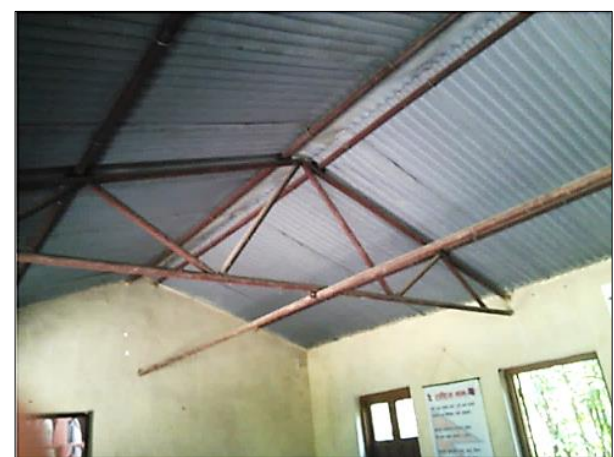

(b)

Figure 4: Photographs representative of the case study URM school building: (a) outside front view and (b) Inside view showing the short walls with gables and light steel roof structure. (Image Copyright: The World Bank)

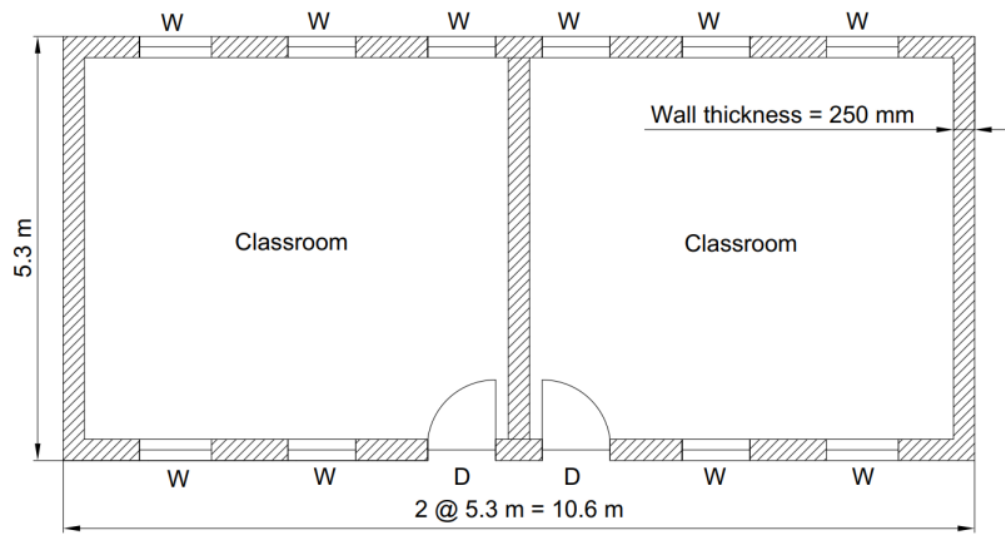

Figure 5: Typical plan of the case study URM school building.

The walls of these buildings are usually constructed in English bond pattern (one brick thick) and the seismic design measures such as horizontal tying elements (e.g. seismic bands) or vertical elements (e.g. posts or corner reinforcements) are usually absent. The openings in long walls are usually large, many and are often placed near to the wall corners.

Present material quality of these buildings varies significantly from one building to another depending on various factors such as date of construction, state of deterioration, maintenance history etc. For the present study, the material properties obtained from in-situ tests on several similar construction types [30], as listed in Table 1, are used. The values of elastic material properties reported in Table 1 are largely dispersed and comparatively lower than those usually reported in literature or suggested in codes and standards [38]. It should be noted that the elastic properties listed here are calculated from the results of in-situ shear tests on existing old buildings.

\begin{tabular}{lll}
\hline Masonry material properties & Average value & CoV \\
\hline Modulus of elasticity & $263 \mathrm{MPa}$ & 0.79 \\
Shear modulus & $158 \mathrm{MPa}$ & 0.79 \\
Compressive strength & $4.14 \mathrm{MPa}$ & NA \\
Cohesion & $0.17 \mathrm{MPa}$ & 0.67 \\
Flexural tensile strength & $0.069 \mathrm{MPa}$ & NA \\
Friction coefficient & 0.6 & NA \\
\hline
\end{tabular}

Table 1: Elastic and non-linear material properties of brick in cement mortar masonry from Nepal. 


\section{ANALYSIS RESULTS AND DISCUSSION}

\subsection{Validation of AEM modelling for lateral behavior of URM walls}

The reliability of the ELS software for the analysis of URM structures is first tested by validating the numerical analysis results with experimental results.

To validate the load-deformation behavior and the failure modes of masonry walls under IP and OOP loadings, two experimental tests are considered: a solid wall with a pre-compression of 1.21 MPa tested by [39] under IP loading and another wall tested by [40] under OOP loading. These are particularly selected for validation because both the inputs i.e. wall model and boundary conditions, material properties and the outputs i.e. load-deformation behavior and failure modes are clearly reported in the literature. Figure 6 and Figure 7 compare the crack patterns at ultimate stage and load-deformation behaviors obtained from the experiment and from numerical analysis in ELS, for IP loading and OOP loading, respectively. For both IP and OOP loading scenarios, the experimental crack patterns are satisfactorily reproduced by the numerical analyses. Also, the initial stiffness, peak strength as well as the ultimate displacement capacity obtained from the numerical analysis are all well correlated with the same obtained from the experiments.

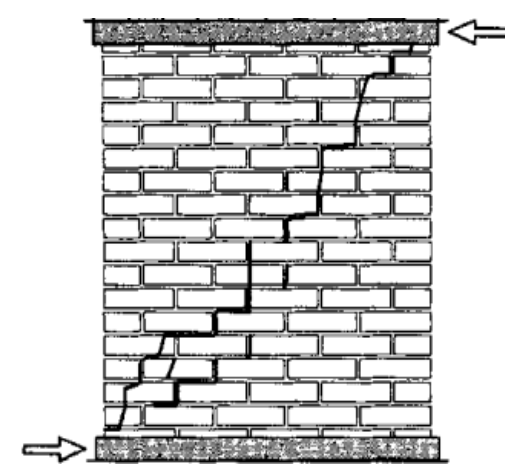

a)

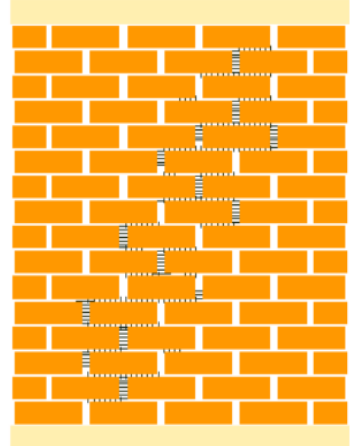

b)

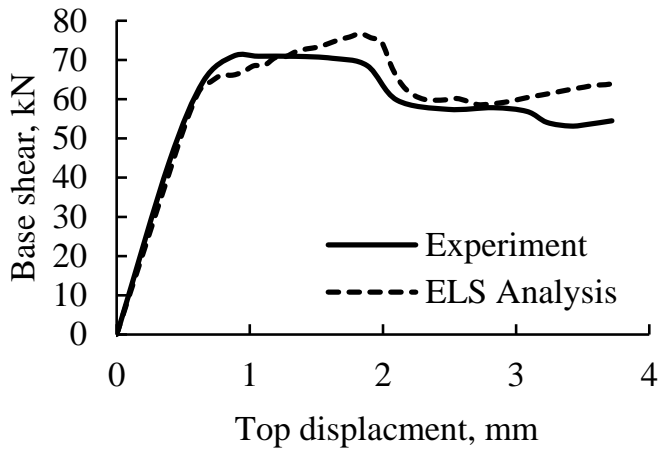

c)

Figure 6: IP behavior: a) Experimental damage pattern at failure (reproduced from [24]), b) Damage pattern (separation cracks) obtained from ELS analysis, and c) Comparison of load-deformation behavior.

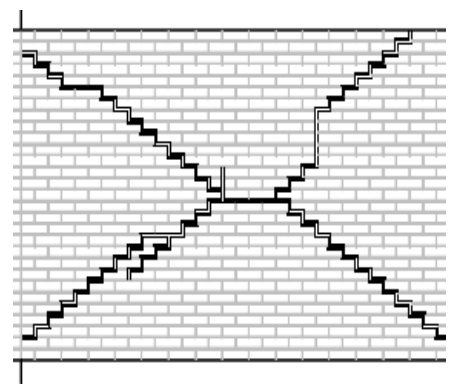

a)

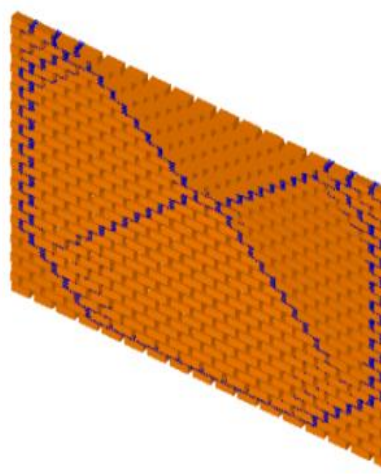

b)

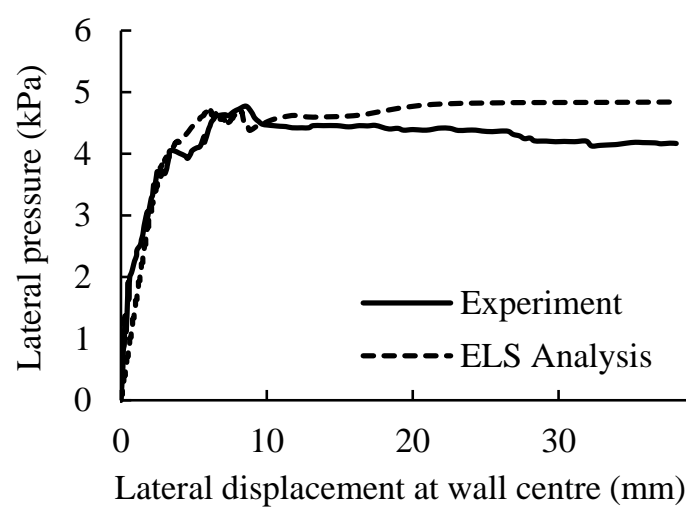

c)

Figure 7: OOP behavior: a) Experimental damage pattern at failure (reproduced from [40]), b) Damage pattern (separation cracks) obtained from ELS analysis, and c) Comparison of load-deformation behavior. 
The validation study revealed that the numerical analyses conducted using the material properties reported in the experimental studies often produce erroneous results that are not in correlation with the experimental results. In general, the elastic material properties i.e. Young's modulus and shear modulus need to be reduced considerably to get numerical results in agreement with the experimental results. The values of elastic material properties reported in the literature are usually obtained from uniaxial compression tests on the masonry prisms and it is reported in a recent study [41] that the elastic properties obtained from prism tests are about $34 \%$ higher than those obtained from wallette tests. Thus, the reported values need to be reduced accordingly in the numerical simulation. Hence, calibrated material properties are used in the numerical analysis in sub-section 4.2.

\subsection{Numerical model of the case study building}

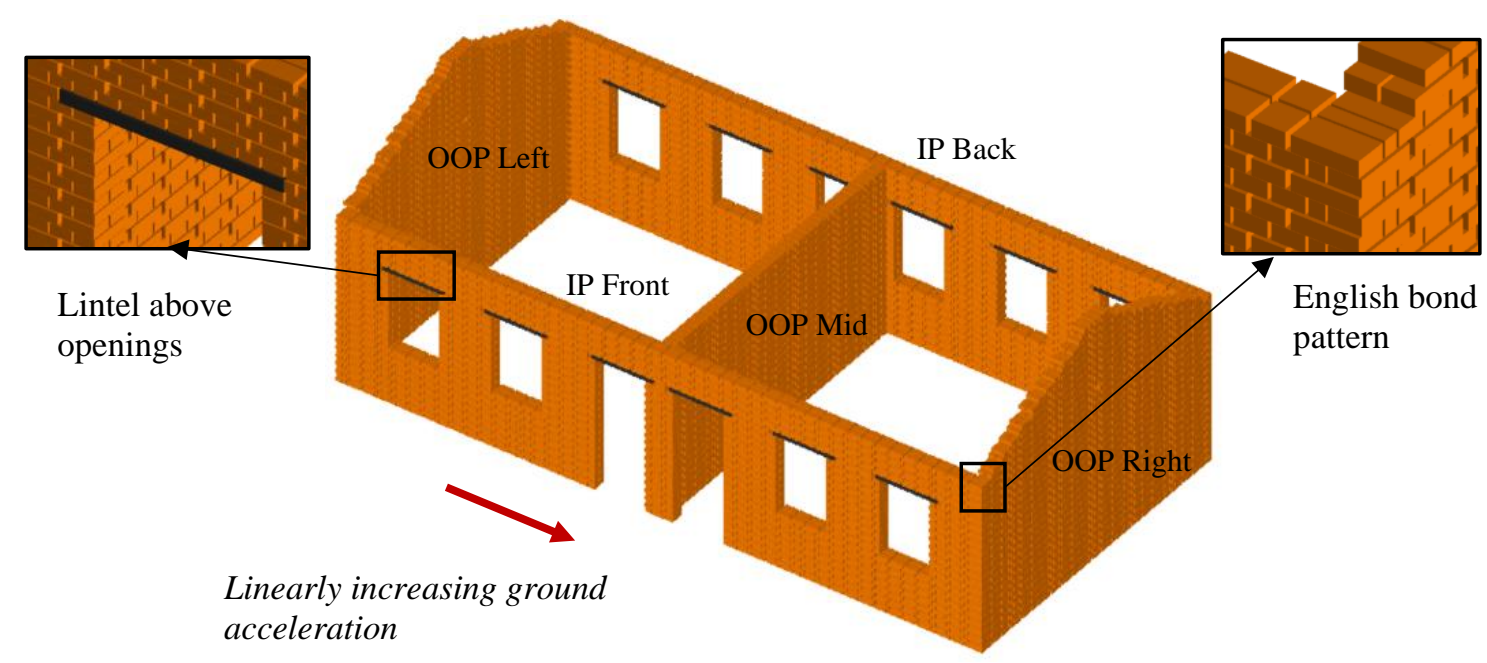

Figure 8: 3-D numerical model of the case study building in ELS using AEM.

In ELS, a 3-D numerical model (Figure 8) of the case study URM building is created using simplified micro-modelling technique. The masonry walls are modelled exactly in the English bond pattern to represent the actual construction. For computational efficiency, bricks are modelled as rigid elements i.e. the cracks are assumed to develop through the mortar joints only. The timber lintels above the openings are modelled as elastic elements. Since the roof in these buildings is light and the roof elements are poorly connected to the masonry walls, it is not modelled structurally, but its weight is directly applied to the top of the walls, as vertical precompression. For the joint springs, a failure criterion is defined by specifying a separation strain, 0.05 for this particular model, obtained from calibration and depending on the maximum crack width. Once this strain limit is exceeded in a spring, the spring is completely removed, after which contact can occur between the applied elements (rigid bodies) depending on the loading condition. The numerical model consists of 12,387 applied elements and $3 \times 3$ sets of springs are used at the interface between any two applied elements. The building is rigidly connected to the ground at its base. The 3-D numerical model is then subjected to a linearly increasing ground acceleration along the longer direction to perform a non-linear pushover analysis.

\subsection{Non-linear pushover analysis results}

In this section, the failure mechanisms and the load-deformation behavior of walls acting in IP and OOP directions are presented and discussed. 


\section{Damage pattern and progression}

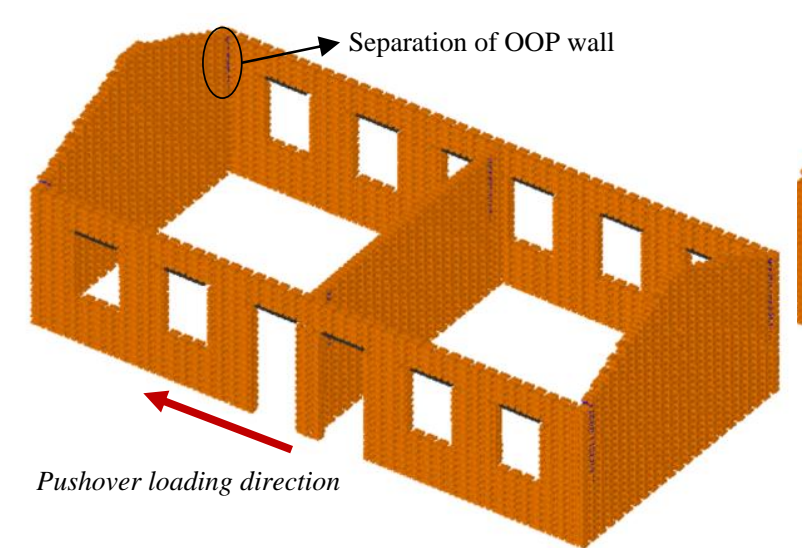

(a) Initiation of OOP -IP connection failure, Loading stage 30

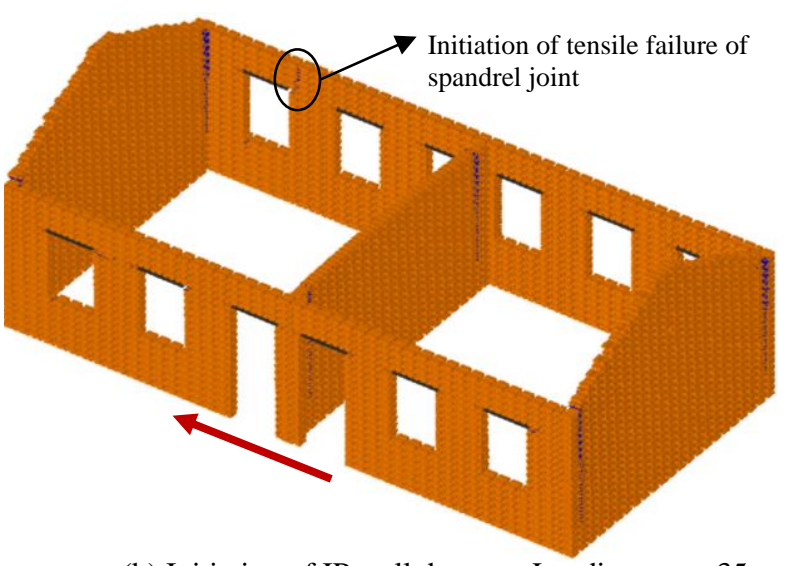

(b) Initiation of IP wall damage, Loading stage 35

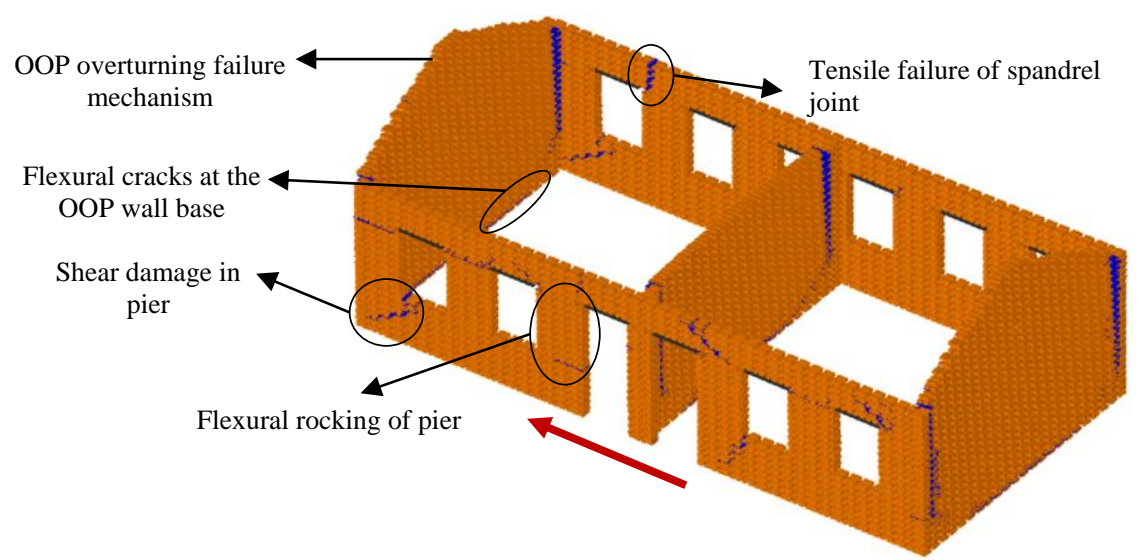

(c) At the end of pushover loading (global collapse), Loading stage 43

Figure 9: Global crack patterns in the building at different stages of pushover loading (blue color represents the major damage cracks, crack width more than $12.5 \mathrm{~mm}$ ).

Figure 9 shows the damage patterns in the case study URM building at different stages of pushover analysis. The evolution of damage shows initially a gradual separation of the OOP walls from the IP walls starting at the top of cross-wall connection (Figure 9(a)). When separation of the connection gradually reaches the lower part, then a horizontal flexural crack starts to develop in the bottom layer of the OOP walls activating the overturning mechanism (Figure 9(c)). Similarly, in the IP walls, the damage starts at the spandrels (Figure 9(b)), then the end piers damage in shear and finally the middle piers start rocking in flexure at the ultimate stage of pushover analysis (Figure 9(c)).

\section{Load-deformation behavior}

Although all the walls have developed collapse mechanisms almost simultaneously for this particular URM building model (Figure 9(c)) which is coincidental, closer analysis of loaddeformation behavior of individual walls reveals that the strength and deformation relationships in the IP and OOP walls are entirely different. The elastic period of vibration of the walls acting in IP direction is about $0.16 \mathrm{~s}$ while the same for the walls acting in OOP direction is as high as $0.3 \mathrm{~s}$. Similarly, once the cracking starts, at any given instant of the loading sequence, the wall 
top displacement in the OOP walls is substantially larger than that in the IP walls, see Figure 10. It is therefore not meaningful to consider the top displacement of any wall, acting either in OOP or IP behavior, as the control node displacement for pushover curve generation for the whole building. Even if one applies some form of simple or weighted average to the displacement, thus derived 'average' global displacement is not realistic as one cannot directly measure it in real buildings nor it is possible to back calculate the individual wall top displacements.

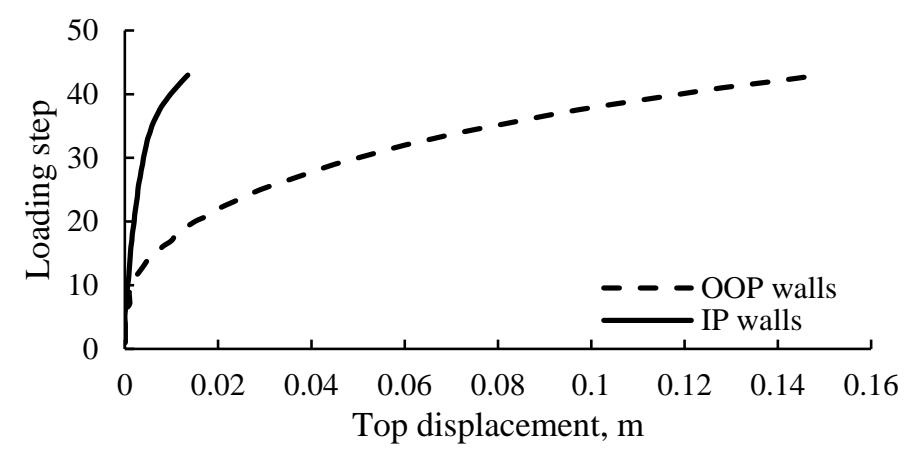

Figure 10. Variation of top displacements in IP and OOP walls under increasing lateral load.

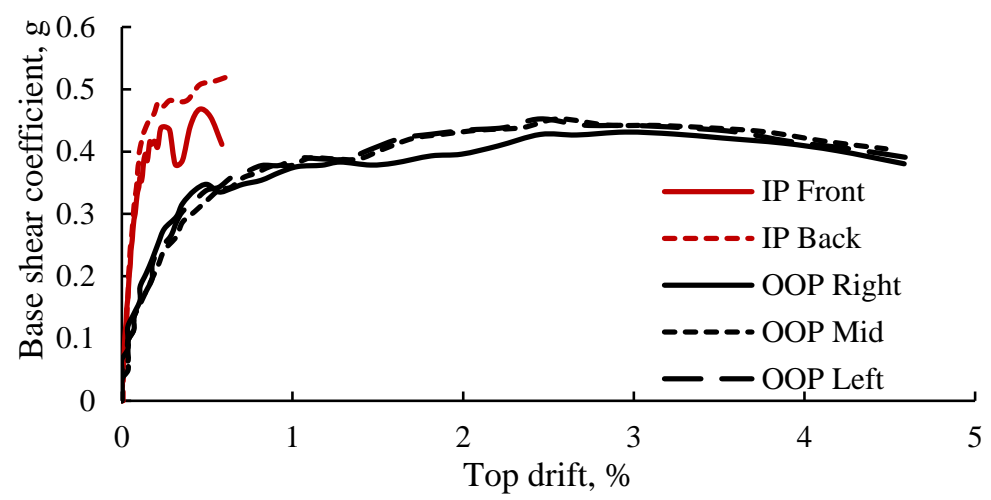

Figure 11: Capacity curves for individual walls acting in IP and OOP direction, respectively (see Figure 8 for wall terminology).

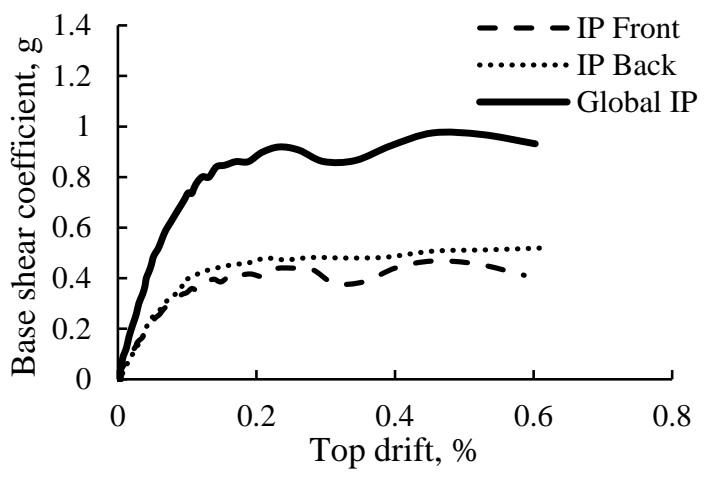

(a)

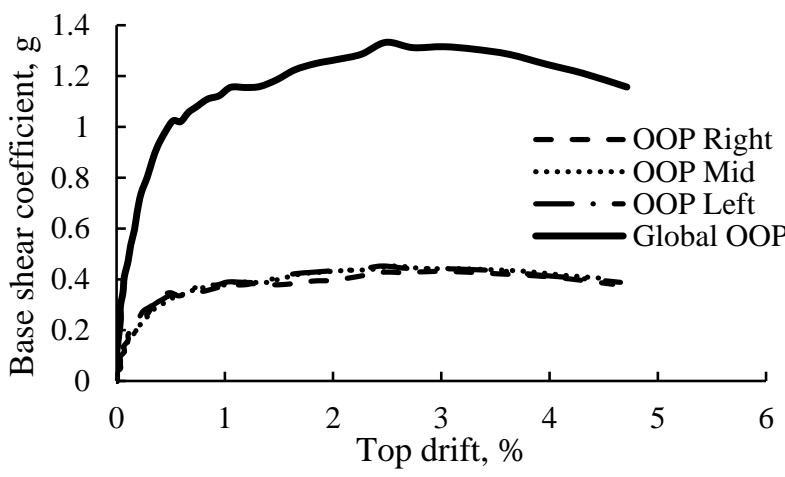

(b)

Figure 12: Global capacity curves for (a) IP behavior and (b) OOP behavior.

Figure 11 shows the capacity curves for individual walls acting in IP and OOP directions. Comparing the initial stiffness, capacity and the lateral displacement, it is clear that it will be entirely wrong to combine these IP and OOP walls having significantly different load- 
deformation behavior to generate a global building level pushover curve and conduct subsequent seismic performance assessment.

However, as the elastic period and the displacement history of all the walls acting in IP behavior and OOP behavior are similar, the global pushover curves for IP and OOP behavior separately are generated as shown in Figure 12 using equations (1) and (2). For efficiency, these capacity curves can be used for the subsequent seismic performance assessments of global IP behavior and global OOP behavior of the building using non-linear static pushover-based procedures [33]. Using this approach, vulnerability functions for global IP and OOP behavior can be generated separately and then combined to obtain the building total vulnerability function.

If the individual walls acting in a particular direction (IP or OOP direction) show dissimilar pushover curves (e.g. because of different wall thickness, opening layouts, connections etc.), then each of the walls should be analyzed separately and the seismic performance assessment becomes similar to a component-based approach, as detailed in FEMA P-58 [42], for example, for reinforced concrete structures.

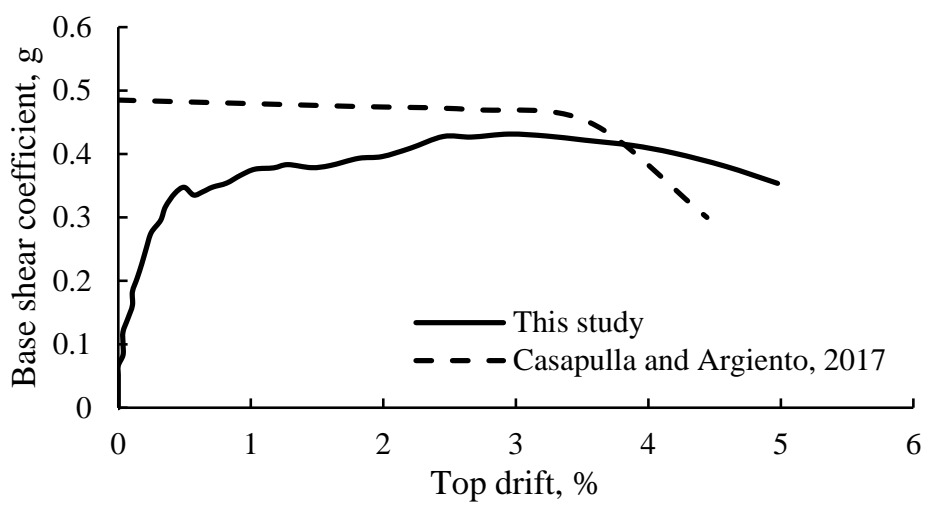

Figure 13: Comparison of OOP pushover curves from this study with the one obtained by using analytical procedure suggested in Casapulla and Argiento [43].

Figure 13 shows a comparison of capacity curves of the walls acting in OOP behavior from this study to those obtained from non-linear kinematic analysis considering frictional resistance at cross-walls as suggested in Casapulla and Argiento [43]. The peak lateral capacity as well as the ductility from both studies show a good match. It indicates that simplified analytical procedures including frictional resistance such as the one used here for comparison seem to be useful for lateral analysis of OOP loaded masonry walls including the effect of friction at cross-wall connections. If the role of friction is neglected, the rigid body analysis of the same wall would yield a lateral capacity of about 0.1 i.e. about $75 \%$ less than the lateral capacity shown in Figure 13. Thus, the role of friction at the connection with the orthogonal walls cannot be neglected.

\section{Is global seismic performance assessment necessary?}

From the literature review and results of this study, it becomes clear that the seismic analysis of URM buildings with flexible diaphragms cannot be reliable when only the IP behavior is considered in the analysis. Conversely, one can argue that in URM buildings with flexible roof diaphragms, the vulnerability analysis of OOP walls might be sufficient when assessing the collapse. It should be noted that the walls acting in OOP behavior have considerable deformation capacity, as seen in the results presented in this study (Figure 11,13) and supported by other experimental studies [15, 40] compared to that of the walls acting in IP behavior. Coincidentally, for this particular case study building, both the IP and OOP walls develop the collapse mechanisms at about the same instant of pushover loading application (refer to Figure 9 (c)). If 
the wall thickness is more, then the walls acting in IP direction might get damaged before the collapse of walls acting in OOP direction as the OOP walls can have stability up to a top displacement equal to the wall thickness for one-way bending [15, 44-45] or even larger in case of two-way bending [11]. Furthermore, when the damage is limited and repairable (i.e. when the building is in slight or moderate damage state), it becomes necessary to understand the damage level in all the walls i.e. global damage level for deciding the repair and retrofit methods, costs etc. Thus, the global analysis of building is important and necessary in post-earthquake damage and repairability assessment as well as in the seismic risk assessment studies of existing URM buildings.

\section{CONCLUSIONS}

- AEM can be used for the 3-D numerical modelling and lateral load analysis of URM structures with reliable accuracy. This has been proven by validations of the IP and OOP behavior of experimentally tested walls and the results of the analysis on a 3-D URM building.

- Application of linearly increasing ground acceleration seems to be an effective method of force-based pushover application in URM buildings with flexible diaphragms.

- In single storied URM buildings with flexible roof diaphragm, the individual walls in IP and OOP direction behave in significantly different manner, and a global pushover curve cannot be generated for reliable non-linear static procedures based seismic performance assessments. Instead, pushover curves for individual walls should be generated which includes the interaction effects with cross-walls; and each wall (acting in IP and OOP direction) needs to be analyzed individually. Global IP or OOP analyses can be conducted in case the pushover curves for all the walls in a particular (IP or OOP) direction are similar.

- The flexible diaphragm is not modelled in this study because of the poor quality of roof connections in the considered building typology from Nepal. However, flexible diaphragms with good connections can alter the failure modes and load-deformation behavior and should be modelled.

\section{ACKNOWLEDGEMENT}

This study is conducted within the 'Global Program for Safer Schools' project of the World Bank which aims to reduce the seismic risk to school infrastructure worldwide. The funding from the World Bank for this research is gratefully acknowledged.

\section{REFERENCES}

[1] L. Decanini, A. De Sortis, A.Goretti, R. Langenbach, F. Mollaioli, A. Rasulo, Performance of masonry buildings during the 2002 Molise, Italy, earthquake. Earthquake Spectra, 20(S1), S191-S220, 2004.

[2] D. F. D'Ayala, S. Paganoni, Assessment and analysis of damage in L'Aquila historic city centre after 6th April 2009. Bulletin of Earthquake Engineering, 9(1), 81-104, 2011.

[3] S. Bhagat, H. A. D. Samith Buddika, R. K. Adhikari, A. Shrestha, S. Bajracharya, R. Joshi, R. Maharjan, A. C. Wijeyewickrema, Damage to cultural heritage structures and buildings due to the 2015 Nepal Gorkha earthquake. Journal of Earthquake Engineering, 22(10), 1861-1880, 2018. 
[4] D. F. D'Ayala, Numerical Modelling of Masonry Structures, M. Forsyth eds. Structures \& Construction in Historic Building Conservation, Blackwell Publishing Ltd., 2008.

[5] D. F. D'Ayala, E. Speranza, Definition of collapse mechanisms and seismic vulnerability of historic masonry buildings. Earthquake Spectra, 19(3), 479-509, 2003

[6] A. Penna, P. Morandi, M. Rota, C. F. Manzini, F. Da Porto, G. Magenes, Performance of masonry buildings during the Emilia 2012 earthquake. Bulletin of Earthquake Engineering, 12(5), 2255-2273, 2014.

[7] M. Tomaževic, M. Lutman, T. Velechovsky, The influence of rigidity of floor on the seismic behavior of old stone-masonry buildings, European Earthquake Engineering 3, 28-41, 1991

[8] G. Magenes, A. Penna, I. E. Senaldi, M. Rota, A. Galasco, Shaking table test of a strengthened full-scale stone masonry building with flexible diaphragms. International Journal of Architectural Heritage, 8(3), 349-375, 2014.

[9] S. J. Lawrence, Behavior of brick masonry walls under lateral loading, PhD Thesis, University of New South Wales, 1983.

[10] K. T. Doherty, An investigation of the weak links in the seismic load path of unreinforced masonry buildings, PhD Thesis, University of Adelaide, 2000.

[11] M. C. Griffith, J. Vaculik, N. T. K. Lam, J. Wilson, E. Lumantarna, Cyclic testing of unreinforced masonry walls in two-way bending. Earthquake Engineering \& Structural Dynamics, 36(6), 801-821, 2007.

[12] J. Vaculik, M. C. Griffith, Out-of-plane shake table testing of unreinforced masonry walls in two-way bending. Bulletin of Earthquake Engineering, 16(7):2839-2876, 2018.

[13] S. Lawrence, R. Marshall, Virtual work design method for masonry panels under lateral load. In Proceedings of $12^{\text {th }}$ International Brick/Block Masonry Conference, 2, 10631073), 2000.

[14] G. D. Felice, R. Giannini, Out-of-plane seismic resistance of masonry walls. Journal of Earthquake Engineering, 5(02), 253-271, 2001.

[15] K. Doherty, M. C. Griffith, N. T. K. Lam, J. Wilson, Displacement-based seismic analysis for out-of-plane bending of unreinforced masonry walls. Earthquake Engineering \& Structural Dynamics, 31(4), 833-850, 2002.

[16] T. M. Ferreira, A. A. Costa, A. Costa, Analysis of the out-of-plane seismic behavior of unreinforced masonry: A literature review. International Journal of Architectural Heritage, 9(8), 949-972, 2015.

[17] L, Sorrentino, D. D’Ayala, G. de Felice, M. C. Griffith, S. Lagomarsino, G. Magenes, Review of out-of-plane seismic assessment techniques applied to existing masonry buildings. International Journal of Architectural Heritage, 11(1), 2-21, 2017.

[18] K. Lang, Seismic vulnerability of existing buildings, PhD Thesis, Swiss Federal Institute of Technology, 2002.

[19] L. Pasticier, C. Amadio, M. Fragiacomo, Non-linear seismic analysis and vulnerability evaluation of a masonry building by means of the SAP2000 V. 10 code. Earthquake Engineering \& Structural Dynamics, 37(3), 467-485, 2008. 
[20] C. Calderini, S. Cattari, S. Lagomarsino, In-plane strength of unreinforced masonry piers. Earthquake Engineering \& Structural Dynamics, 38(2), 243-267, 2009.

[21] F. Buchhi, S. Arangio, F. Bontempi, Seismic assessment of historical masonry buildings with nonlinear static analysis. B.H.V. Topping and P. Iványi, eds, $14^{\text {th }}$ International Conference on Civil, Structural and Environmental Engineering Computing, Italy, 2013.

[22] Applied Technology Council, ATC-40: Seismic Evaluation and Retrofit of Concrete Buildings, Vol. 1 \& 2, Applied Technology Council, CA, USA, 1996.

[23] P. Fajfar, A nonlinear analysis method for performance-based seismic design. Earthquake Spectra, 16(3), 573-592, 2000.

[24] P. B. Lourenço, J. G. Rots, Multi-surface interface model for analysis of masonry structures. Journal of Engineering Mechanics, 123(7), 660-668, 1997.

[25] J. V. Lemos, Discrete element modeling of masonry structures. International Journal of Architectural Heritage, 1(2), 190-213, 2007.

[26] D. Malomo, R. Pinho, A. Penna, Using the applied element method for modelling calcium silicate brick masonry subjected to in-plane cyclic loading. Earthquake Engineering \& Structural Dynamics, 47(7), 1610-1630, 2018.

[27] S. Lagomarsino, A. Penna, A. Galasco, S. Cattari, TREMURI program: an equivalent frame model for the nonlinear seismic analysis of masonry buildings. Engineering Structures, 56, 1787-1799, 2013.

[28] K. Meguro, H. Tagel-Din, Applied element method for structural analysis, Doboku Gakkai Ronbunshu, 2000(647), 31-45, 2000.

[29] A. Karbassi, M. J. Nollet, Performance-based seismic vulnerability evaluation of masonry buildings using applied element method in a nonlinear dynamic-based analytical procedure, Earthquake Spectra, 29(2), 399-426, 2013.

[30] R. Guragain, Development of earthquake risk assessment system for Nepal, PhD Thesis, University of Tokyo, 2015.

[31] ASI, Extreme Loading for Structures V6. Applied Science International LLC, Durham (NC), USA, 2018.

[32] FEMA, FEMA 440: Improvement of nonlinear static seismic analysis procedures, Federal Emergency Management Agency, Washington, D.C., USA, 2005.

[33] D. F. D’Ayala, A. Meslem, D. Vamvatsikos, K. Porter, T. Rossetto, Guidelines for analytical vulnerability assessment - low/mid-rise. GEM Technical Report, GEM Foundation, Pavia, Italy, 2015.

[34] DRES, A preliminary report on school buildings performance during M 7.3 Ezgeleh, Iran earthquake of November 12, 2017, Organization for Development, Renovation and Equipping Schools of I. R. Iran, 2017.

[35] M. Schildkamp, Y Araki, School buildings in rubble stone masonry with cement mortar in seismic areas: literature review of seismic codes, technical norms and practical manuals. Front. Built Environ, 5:13 2019.

[36] SIDA, Structural Integrity and Damage Assessment for Educational Infrastructures in Nepal, Phase I and II: Results and Finding. SIDA Report, The World Bank, 2016 
[37] N. Peiris, T. Rossetto, P. Burton, S. Mahmood, The Kashmir, Pakistan earthquake of 8 October 2005, EEFIT Report, Institution of Structural Engineers, UK, 2008.

[38] FEMA, Pre-standard and commentary for the seismic rehabilitation of buildings, Federal Emergency Management Agency, Washington, D.C., USA, 2000.

[39] A. T. Vermeltfoort, T. M. J. Raijmakers, and H. J. M. Janssen, Shear tests on masonry walls. Proceeding of $6^{\text {th }}$ North American Masonry Conference, Philadelphia, USA, 1993.

[40] J. Vaculik, Unreinforced masonry walls subjected to out-of-plane seismic actions. PhD Thesis, University of Adelaide, 2012.

[41] J. A. Thamboo, M. Dhanasekar, Correlation between the performance of solid masonry prisms and wallettes under compression. Journal of Building Engineering, 22, 429-438, 2019.

[42] FEMA, FEMA P-58: Seismic performance assessment of buildings, Volume I - methodology, Federal Emergency Management Agency, Washington, D.C., USA, 2012.

[43] C. Casapulla, L. Argiento, Non-linear kinematic analysis of masonry walls out-of-plane loaded. The comparative role of friction between interlocked walls. In Proceedings of the COMPDYN 2017: $6^{\text {th }}$ ECCOMAS Thematic Conference on Computational Methods in Structural Dynamics and Earthquake Engineering, Rhodes Island, Greece, 2017

[44] H. Derakhshan, M. C. Griffith, J. M. Ingham, Out-of-plane behavior of one-way spanning unreinforced masonry walls. Journal of Engineering Mechanics, 139(4), 409-417, 2011.

[45] O. Penner, K. J. Elwood, Out-of-plane dynamic stability of unreinforced masonry walls in one-way bending: shake table testing. Earthquake Spectra, 32(3), 1675-1697, 2016. 